\title{
Basic characteristics and quality of virgin olive oil produced in Corfu (cv. Lianolia) and South Albania (cv. Kalinioti)
}

\author{
Konstantoula Akrida-Demertzi ${ }^{1}$, Christos Roukos ${ }^{2}$ and Panagiotis Demertzis ${ }^{1}$ \\ 1 University of Ioannina, Department of Chemistry, Laboratory of Food Chemistry, \\ 45500 Ioannina, Greece \\ 2 Ministry of Rural Development and Food, Regional Department of Epirus \& Western Greece, \\ Terma Panepistimiou Str, 45110 Ioannina, Greece
}

\begin{abstract}
In the present study the qualitative characteristics such as peroxide number, absorption coefficients $\left(\mathrm{K}_{232}\right.$, $\mathrm{K}_{270}$ ), acidity, total phenols, a-tocopherols, chlorophylls and composition of fatty acids were determined in 19 virgin olive oil samples of "Lianolia" variety cultivated in Corfu and "Kalinioti" variety cultivated in South Albania, harvested in the crop year 2013/2014.

Obtained results indicate that all olive oil samples show chemical and physicochemical parameters included in the limits established for virgin olive oils and some of them in the limits for "extra" virgin olive oils.

Moreover it was found that the qualitative characteristics of olive oil samples are affected by variety, fruit treatment and the method of olive harvesting (in Corfu olives are collected by hands from plastic nets under the trees, whereas in Albania they are basically collected by hand after falling on the ground). The results of the present study are a first indication of the olive oil quality produced in Corfu and South Albania.
\end{abstract}

Keywords: Virgin olive oil; total phenols; a-tocopherols; chlorophylls; fatty acids

\section{Introduction}

Virgin olive oil (VOO) is the supernatant of the natural juice obtained exclusively by mechanical and physical processes from fresh and healthy olive fruits (Olea europea L.), such as washing, pressing, malaxation of olive paste, centrifugation, decantation, and filtration that do not modify its characteristics [1]. Virgin olive oil is a main agriculture product and plays an important role in the Greek agronomy and economy in Greece which is ranked third after Spain and Italy. The annual production is around $310.000 \mathrm{t}$ olive oil produced from 531.000 oil farms, covering a total of $\sim 730.000$ ha, and the annual olive oil consumption is estimated around $220.000 \mathrm{t}$. [2].

Nowadays, it is well-known that regular dietary consumption of virgin olive oil manifests in health benefits associated with Mediterranean diet. The nutritional value of virgin olive oil arises from high level of oleic acid and from minor components such as phytosterols, carotenoids, tocopherols and total phenols. The major phenolic compounds are oleuropein derivatives, based on hydroxytyrosol, which are strong antioxidants and radical scavengers [3]. Considering that virgin olive oil is obtained from the olive fruit solely by mechanical and physical means, it retains more health beneficial phytochemicals as compared to other commercially available refined vegetable oils, which are generally solvent extracted [4].

Among minor components of olive oil, tocopherols and phenolic compounds represent antioxidants. In particular, phenolics make important contribution to the nutritional properties, the sensory characteristics, and the shelf life of olive oil. Indeed, it is known that the healthy properties of the phenolic compounds are correlated to their antioxidant activity [5].

The definition of the quality features of every edible product is of particular interest to both consumers and producers. Consequently it is justifiably necessary to define the quality level of olive oil which is an essential agricultural product of Greece and South Albania [6]. 
In the present study the quality characteristics such as peroxide number, absorption coefficients $\left(\mathrm{K}_{232}, \mathrm{~K}_{270}\right)$, acidity, total phenols, a-tocopherols, chlorophylls and composition of fatty acids were determined in 19 virgin olive oil samples of "Lianolia" variety cultivated in Corfu-Greece and "Kalinioti" variety cultivated in South Albania, harvested in the crop year 2013/2014.

The main objective of the present study was to investigate how olive oil quality is affected by variety and harvesting time and for this reason the two most common varieties in Corfu and South Albania ("Lianolia" and "Kalinioti") were comparatively studied.

\section{Materials}

Samples: 15 virgin olive oil samples of "Lianolia" variety cultivated in Corfu and "Kalinioti" variety cultivated in South Albania, collected in the crop year 2013/2014, were used for physicochemical analysis

Reagents and standards: The standards of methyl palmitate, methyl palmitoleate, methyl stearate, methyl oleate, methyl linolate and methyl linolenate were purchased from Sigma- Aldrich (Steinhaim, Germany). Methanol, n-hexane and 1-propanol were all of HPLC grade and were purchased from Lab-scan, Gliwice, Poland.

\section{Apparatus:}

-Spectrophotometer Milton Roy 1201

-A Shimadzu HPLC system (Shimadzu Corporation, Kyoto, Japan) consisting of a solvent delivery module (LC-10AD) with a double plunger reciprocating pump, UV-VIS detector (SPA-10A), column oven (CTO10A) and $20 \mu \mathrm{l}$ injection loop was used. The column used was an RP-Apex octadecyl $\mathrm{C}_{18}(15 \mathrm{x} 0.4 \mathrm{~cm}$ i.d.) with $5 \mu \mathrm{m}$ packing (Jones Chromatography limited, Colorado, USA).

-Gas Chromatograph Fisons GC-9000 series equipped with capillary column Carbowax 30m x 0.32mm i.d and FID detector.

\section{Analytical Methodology \\ Free Acidity, Peroxide number, Specific UV Absorbances, Chlorophyll content, Polyphenols and $\alpha$ - tocopherols}

Acidity (given in \% of oleic acid) was measured by volumetric analysis [7].

Peroxide number (meq/Kg) and absorption coefficients $\left(\mathrm{K}_{232}\right.$ and $\left.\mathrm{K}_{270}\right)$ were determined according to 2.501 and 2.505 IUPAC methods [8].

Chlorophyll content was measured according to AOCS method [9].

Polyphenols (Total Phenolic Content-TPC) were determined by colorimetric Folin Ciocalteu method. Phenolic compounds were isolated by a triple extraction with a methanol/water mixture $(60: 40, \mathrm{v} / \mathrm{v})$. The Folin-Ciocalteu reagent was added to a suitable aliquot of the combined extracts, and the absorption of the solution was measured spectrophotometrically at $725 \mathrm{~nm}$. The total phenols were expressed as mg caffeic acid/kg oil using a standard curve (calibration curve with $\mathrm{r}^{2}=0.99$ ) [6].

$\alpha$-tocopherols were analyzed by HPLC at $294 \mathrm{~nm}$ using UV-VIS detector. Olive oil solutions ( $8 \% \mathrm{w} / \mathrm{v}$ ) were prepared in a solvent mixture $\mathrm{n}$-haxane/2-propanol 99:1 $\mathrm{v} / \mathrm{v}$ and filtered through a $0.45 \mu \mathrm{m}$ membrane filter. n-Hexane/2-propanol (99:1) v/v (A) and 2-propanol (B) were used as eluents. The gradient was 0\% B for 10 $\min 0-5 \% \mathrm{~B}$ in $4 \mathrm{~min}, 5 \% \mathrm{~B}$ for $6 \mathrm{~min}, 5-0 \% \mathrm{~B}$ in $4 \mathrm{~min}$ and $0 \% \mathrm{~b}$ for $6 \mathrm{~min}$. Separation was achieved on a $150 \mathrm{~mm} \mathrm{C18}$ column at a $1.2 \mathrm{ml} / \mathrm{min}$ flow rate. The injection volume was $20 \mu \mathrm{l}$. $\alpha$-tocopherol standard solutions were prepared in solvent A. Tocopherols were detected at $294 \mathrm{~nm}$ by the UV-VIS detector and for quantification standard curves (concentration versus peak area) were calculated by linear regression analysis. Injections in duplicate were made at each concentration for both standards and samples [8-13].

Fatty acid analysis was performed by GC (8). A chromatographic analysis was performed in a Fisson 9000 gas chromatography, equipped with a FID detector and a Thermo Quest auto sampler using a capillary DBwax column (length $30 \mathrm{~m}$, internal diameter $0.32 \mathrm{~mm}$ and thickness $0.32 \mu \mathrm{m}$ ). The following GC parameters were kept constant: detector temperature: $240{ }^{0} \mathrm{C}$, injector temperature: $220{ }^{0} \mathrm{C}$, injector mode: split with split ratio 1:18, injection volume $1 \mu \mathrm{l}$. The applied temperature program was $180{ }^{\circ} \mathrm{C}(5 \mathrm{~min})$, from $180{ }^{\circ} \mathrm{C}$ at a rate of $3{ }^{\circ} \mathrm{C} / \mathrm{min}$ to $210{ }^{\circ} \mathrm{C}(20 \mathrm{~min})$, cooling rate $50{ }^{\circ} \mathrm{C} / \mathrm{min}$ to final $180{ }^{\circ} \mathrm{C}$. Fatty acids were identified by comparing retention times with standard compounds. 


\section{Statistical analyses}

Data were statistically analyzed using a factorial design where harvesting time $(n=3)$ and sites $(n=5)$ are the study factors, with interaction between harvesting time and sites [10]. The interaction harvesting time $\times$ sites was significant $(\mathrm{P}<0.05)$, thus analyses of variance were conducted among harvesting times and among sites within harvesting times. Significant mean differences were detected using least square differences [11]. Pearson's correlations were calculated to examine interactions between quality parameters [11]. Differences were considered significant at the $\mathrm{p}<0.05$ level.

\section{Results and Discussion}

In order to carry out the present investigation, the area of Albania was divided into 3 zones (Mountainous, Field and Coastal) and Corfu into 2 zones (North and South) i.e. into zones with different soil-climate characteristics. In the existing olive groves of every zone, an experimental field, planted with the above mentioned varieties and being of a suitable size, was chosen.

Olive fruit samples used for the production of olive oil to be analyzed were harvested from the above experimental fields. The samples were collected in three different periods: end of November, end of December and end of January. In Corfu olives are harvested by hands from plastic nets under the trees, whereas in Albania they are basically harvested by hand after falling on the ground.

In Table 1 data on origin, harvesting and storage of olives from "Lianolia" and "Kalinioti" varieties used for olive oil production as well as the type of olive mill are given.

Table 1. Data on origin, harvesting and storage method of olives from "Lianolia" and "Kalinioti" varieties and type of olive mill.

\begin{tabular}{|c|c|c|c|c|c|c|c|c|}
\hline $\begin{array}{l}\text { Sample } \\
\text { number }\end{array}$ & Area & Variety & Site & $\begin{array}{l}\text { Harvesting } \\
\text { time }\end{array}$ & $\begin{array}{l}\text { Harvesting } \\
\text { method }\end{array}$ & $\begin{array}{l}\text { Storage } \\
\text { time }\end{array}$ & $\begin{array}{l}\text { Storage } \\
\text { method }\end{array}$ & $\begin{array}{l}\text { Olive mill } \\
\text { type }\end{array}$ \\
\hline 1 & South Albania & Kalinioti & $\mathrm{A}$ & End of November & \multirow{15}{*}{ By hand } & \multirow{15}{*}{5 days } & \multirow{15}{*}{ In sacks } & \multirow{15}{*}{ Centrifugal } \\
\hline 6 & South Albania & Kalinioti & $A$ & End of December & & & & \\
\hline 7 & South Albania & Kalinioti & $A$ & End of January & & & & \\
\hline 2 & South Albania & Kalinioti & $B$ & End of November & & & & \\
\hline 5 & South Albania & Kalinioti & B & End of December & & & & \\
\hline 8 & South Albania & Kalinioti & B & End of January & & & & \\
\hline 3 & South Albania & Kalinioti & $\mathrm{C}$ & End of November & & & & \\
\hline 4 & South Albania & Kalinioti & $\mathrm{C}$ & End of December & & & & \\
\hline 9 & South Albania & Kalinioti & $\mathrm{C}$ & End of January & & & & \\
\hline 10 & Corfu & Lianolia & $\mathrm{D}$ & End of November & & & & \\
\hline 11 & Corfu & Lianolia & $\mathrm{D}$ & End of December & & & & \\
\hline 12 & Corfu & Lianolia & $\mathrm{D}$ & End of January & & & & \\
\hline 13 & Corfu & Lianolia & $E$ & End of November & & & & \\
\hline 14 & Corfu & Lianolia & $E$ & End of December & & & & \\
\hline 15 & Corfu & Lianolia & $E$ & End of January & & & & \\
\hline
\end{tabular}

The quality characteristics of the investigated virgin olive oil samples are given in Table 2 .

The chemical composition and quality of virgin olive oil are influenced by a variety of factors among them are geographical production area (altitude, soil composition, latitude) climatic conditions prevalent in the year of production, the cultivar and the extraction process [12].

In Table 3 the correlation coefficients between harvest time and quality characteristics of olive oil from five different sites are presented. During the study period, as ripening progresses, concentrations of $\alpha$ tocopherols, and peroxide number increased significantly. Total polyphenols and chlorophyll contents showed significant $(\mathrm{P}<0.01)$ negative correlation with increasing level of maturation.

The quality characteristics of olive oil produced at the 5 different sites in relation to harvesting time are given in table 4.

Based on the data from Tables 2 and 4 and the national and European legislation [13, 14], it is noted that acidity, peroxide number and absorption coefficients $\left(\mathrm{K}_{232}, \mathrm{~K}_{270}\right)$ values for all samples show that they belong to the category of virgin olive oil. 3 samples $(11,12$ and 15) belong to the category of extra virgin olive oil, 2 samples ( 9 and 14) to the category of lampante virgin olive oil [6, 13-18]. 
Acidity values show considerable variations among the studied samples of both varieties. These variations can be mainly attributed to the different harvesting techniques followed in Corfu and S. Albania.

Except for the first harvesting time (end of November), the acidity in all olive oil samples was significantly different among sites and among sites within harvest times,

Olive oil samples from Site $\mathrm{C}$ had the highest acidity values, while samples from Site D the lowest (Table 4). The most of the olive oil samples exhibited their peak values in acidity content at the second harvesting time (end of December).

Furthermore, peroxide number values vary among the studied varieties. Slightly variations are also observed in relation with both harvesting method and zone origin of olives.

Absorption coefficients values are within the limits established for edible virgin olive oils [6, 13-18]

The concentration of polyphenols and tocopherols is more or less influenced by the variety, harvesting time and harvesting method. The concentrations of total phenols for the studied samples were between 32.05 and $199.47 \mathrm{mg} / \mathrm{kg}$. Similar concentrations for these ingredients in Greek olive oils were reported by other researchers [2].

Also the $\alpha$-tocopherol $(\alpha-\mathrm{T})$ concentrations for the studied samples were found between 47.39 and 158.54 $\mathrm{mg} / \mathrm{kg}$. Past food chemistry reference books reported rather low levels of $\alpha$-T for olive oils $(<150 \mathrm{mg} / \mathrm{kg})$. The concentration of $\alpha-\mathrm{T}$ in a virgin olive oil depends on pedoclimatic, agronomic and technological factors. Genetic factors in some cases are becoming important. Current legislation on health claims gives an opportunity for advertisement of virgin olive oil as a good source of vitamin E and points to an urge for systematic knowledge of the potential of different olive cultivars and technological systems to yield extra virgin olive oil of high content in this bioactive compound. Moreover, its levels in commercial products should be also examined. Industrial and domestic handling conditions and practices are also critical factors for the maintenance of the prone to oxidation $\alpha-T$. The recognition of the health benefits of polar phenolic compounds together with the fact that virgin olive oil is a good source of vitamin $\mathrm{E}$ are expected to influence consumption of virgin olive oil worldwide if their contents are in line with legislative requirements [2].

The polyphenols content in all olive oil samples was significantly different among sites and among sites within harvesting times (Table 4). During harvesting period (November through January) polyphenols contents of olive oils samples from Site A and B, showed a decrease with time of harvest. Total polyphenol level in the present study showed a clear negative correlation with increasing levels of maturation. Similar results were reported by other investigators [12].

Polyphenol content of oil strongly influences its oxidative stability, nutritional properties and flavor. The extent of quality deterioration of virgin olive oil depends on the storage conditions e.g. temperature, light, presence of oxygen in headspace, headspace volume, and on the package material. The changes expected are mainly caused by hydrolytic and oxidative phenomena. During storage, virgin olive oil antioxidants, as more oxidisable, contribute to extending the shelf life of the polyunsaturated fatty acids. The changes in the content and type of polyphenolic constituents affect the sensory characteristics of the oil. Less bitter and pungent oils are obtained even after six months of storage [2].

Chlorophyll content in the studied samples was ranged between 0.03 and $11.05 \mathrm{ppm}$ and its content seems to be mainly depended on the variety and the harvesting method. As ripening progresses, photosynthetic activity decreases and the concentrations of chlorophylls decrease progressively [12]. Similar chlorophyll concentrations were found in virgin olive oil samples from other countries, in particular from Tunisia [1921].

Variations in oleic acid content were observed among olive tree varieties and zone of origin.

Finally, variations in the ratios of unsaturated/ saturated and monounsaturated/ polyunsaturated fatty acids among the studied varieties were observed.

In conclusion, obtained results, although preliminary, could give a first indication of the quality of olive oil produced in Corfu and S. Albania. 
Table 2: Results of two-way ANOVA showing degrees of freedom, F-statistic and the significance of the effects of harvesting time and sites interactions on quality characteristics of studied olive oil.

\begin{tabular}{|c|c|c|c|c|c|c|c|c|c|c|c|}
\hline \multirow{2}{*}{$\begin{array}{l}\text { Source of } \\
\text { variation }\end{array}$} & \multirow[t]{2}{*}{ d.f. } & \multicolumn{2}{|c|}{ Acidity } & \multicolumn{2}{|c|}{ Polyphenols (mg/Kg) } & \multicolumn{2}{|c|}{$\begin{array}{c}\alpha \text {-Tocopherols } \\
(\mathrm{mg} / \mathrm{Kg})\end{array}$} & \multicolumn{2}{|c|}{$\begin{array}{l}\text { Peroxide Number } \\
(\mathrm{meq} / \mathrm{Kg})\end{array}$} & \multicolumn{2}{|c|}{ Methyl Palmitoleate \% } \\
\hline & & $\mathbf{F}$ & $\mathbf{P}$ & $\mathbf{F}$ & $\mathbf{P}$ & $\mathbf{F}$ & $\mathbf{P}$ & $\mathbf{F}$ & $\mathbf{P}$ & $\mathbf{F}$ & $\mathbf{P}$ \\
\hline Site (S) & 4 & 192,796 & 0,000 & 338,020 & 0,000 & 5779,442 & 0,000 & 313,551 & 0,000 & 35,375 & 0,000 \\
\hline Harvest Time $(\mathrm{H})$ & 2 & 14,171 & 0,000 & 2529,660 & 0,000 & 240,103 & 0,000 & 454,399 & 0,000 & 3,549 & 0,041 \\
\hline \multirow[t]{2}{*}{$\mathrm{S} \times \mathrm{H}$} & 8 & 148,294 & 0,000 & 1258,448 & 0,000 & 536,486 & 0,000 & 209,401 & 0,000 & 4,829 & 0,001 \\
\hline & & \multicolumn{2}{|c|}{$\mathrm{UV} \mathrm{K}_{232}$} & \multicolumn{2}{|c|}{$\mathrm{UV} \mathrm{K} \mathrm{K}_{270}$} & \multicolumn{2}{|c|}{ Chlorophyll (ppm) } & \multicolumn{2}{|c|}{ Methyl Palmitate \% } & \multicolumn{2}{|c|}{ Methyl Stearate \% } \\
\hline $\begin{array}{l}\text { Source of } \\
\text { variation }\end{array}$ & d.f. & $\mathbf{F}$ & $\mathbf{P}$ & $\mathbf{F}$ & $\mathbf{P}$ & $\mathbf{F}$ & $\mathbf{P}$ & $\mathbf{F}$ & $\mathbf{P}$ & $\mathbf{F}$ & $\mathbf{P}$ \\
\hline Site (S) & 4 & 4,691 & 0,005 & 5,598 & 0,002 & 6025,597 & 0,000 & 7717,999 & 0,000 & 364,316 & 0,000 \\
\hline Harvest Time $(\mathrm{H})$ & 2 & 12,089 & 0,000 & 11,413 & 0,000 & 4913,542 & 0,000 & 847,692 & 0,000 & 11,169 & 0,000 \\
\hline \multirow[t]{2}{*}{$\mathrm{S} \times \mathrm{H}$} & 8 & 41,907 & 0,000 & 15,543 & 0,000 & 4845,205 & 0,000 & 1419,258 & 0,000 & 35,282 & 0,000 \\
\hline & & \multicolumn{2}{|c|}{ Methyl Oleate \% } & \multicolumn{2}{|c|}{ Methyl Linoleate \% } & \multicolumn{2}{|c|}{$\begin{array}{l}\text { Methyl Linolenate } \\
\%\end{array}$} & & & & \\
\hline $\begin{array}{l}\text { Source of } \\
\text { variation }\end{array}$ & d.f. & $\mathbf{F}$ & $\mathbf{P}$ & $\mathbf{F}$ & $\mathbf{P}$ & $\mathbf{F}$ & $\mathbf{P}$ & & & & \\
\hline Site (S) & 4 & 1012,495 & 0,000 & 763,902 & 0,000 & 341,419 & 0,000 & & & & \\
\hline Harvest Time $(\mathrm{H})$ & 2 & 170,289 & 0,000 & 346,745 & 0,000 & 215,755 & 0,000 & & & & \\
\hline $\mathrm{S} \times \mathrm{H}$ & 8 & 109,403 & 0,000 & 86,043 & 0,000 & 431,906 & 0,000 & & & & \\
\hline
\end{tabular}

Table 3. Correlation coefficients between harvest time and quality characteristics of olive oil from five different sites.

\begin{tabular}{|c|c|c|c|c|c|c|c|c|c|c|c|c|}
\hline & $\begin{array}{l}\text { Harvesting } \\
\text { time }\end{array}$ & Acidity & Polyphenols & $\begin{array}{c}\alpha- \\
\text { Tocopherol } \\
s\end{array}$ & $\begin{array}{c}\text { Peroxide_N } \\
\text { umber }\end{array}$ & Chlorophyll & $\begin{array}{l}\text { Methyl_Pal } \\
\text { mitate_\% }\end{array}$ & $\begin{array}{c}\text { Methyl_Pal } \\
\text { mitoleate_ } \\
\%\end{array}$ & $\begin{array}{l}\text { Methyl_Ste } \\
\text { arate_\% }\end{array}$ & $\begin{array}{l}\text { Methyl_Ole } \\
\text { ate_\% }\end{array}$ & $\begin{array}{c}\text { Methyl_Lin } \\
\text { oleate_\% }\end{array}$ & $\begin{array}{l}\text { Methyl_Lin } \\
\text { olenate_\% }\end{array}$ \\
\hline Harvesting time & 1 & & & & & & & & & & & \\
\hline
\end{tabular}




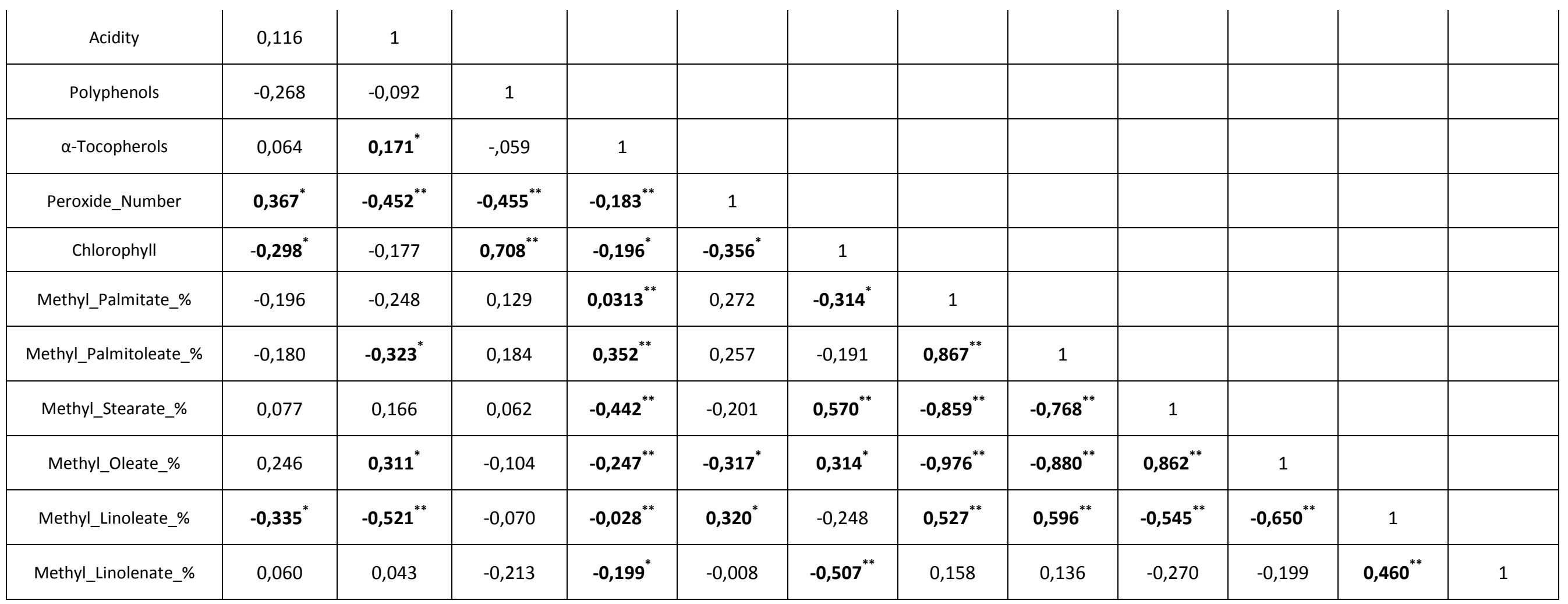

$*: \mathrm{P}<0.05, * *: \mathrm{P}<0,01$ 
Table 4. Mean values of olive oil quality characteristics produced at five (5) different sites in relation to harvesting time.

\begin{tabular}{|c|c|c|c|c|c|c|c|c|}
\hline & Site A & Site B & Site C & Site D & Site $\mathrm{E}$ & Mean & SEM & Sig. \\
\hline & \multicolumn{8}{|c|}{ Acidity } \\
\hline End of November & 0,93 & 1,63 & 1,47 & 0,87 & 1,56 & 1,29 & 0,063 & $* * *$ \\
\hline End of December & 1,53 & 1,43 & 1,26 & 0,57 & 2,37 & 1,43 & 0,079 & $* * *$ \\
\hline End of January & 1,71 & 1,87 & 3,07 & 0,43 & 0,38 & 1,49 & 0,108 & $* * *$ \\
\hline Mean & 1,39 & 1,64 & 1,93 & 0,62 & 1,44 & 1,41 & & \\
\hline SEM & 0,112 & 0,082 & 0,128 & 0,047 & 0,107 & & & \\
\hline \multirow[t]{2}{*}{ Sig. } & $* * *$ & $* *$ & $* * *$ & $* * *$ & $* * *$ & & & \\
\hline & \multicolumn{8}{|c|}{ Polyphenols (mg/Kg) } \\
\hline End of November & 171,3 & 77,6 & 48,1 & 85,9 & 52,3 & 87,0 & 1,30 & $* * *$ \\
\hline End of December & 45,3 & 73,9 & 177,4 & 173,6 & 136,6 & 121,4 & 1,95 & $* * *$ \\
\hline End of January & 50,6 & 54,4 & 79,2 & 53,1 & 36,6 & 54,8 & 2,76 & $* * *$ \\
\hline Mean & 89,1 & 68,6 & 101,6 & 104,2 & 75,2 & 87,7 & & \\
\hline SEM & 1,61 & 1,61 & 2,84 & 2,51 & 5,87 & & & \\
\hline \multirow[t]{2}{*}{ Sig. } & $* * *$ & $* * *$ & $* * *$ & $* * *$ & $* * *$ & & & \\
\hline & \multicolumn{8}{|c|}{$\alpha$-Tocopherols (mg/Kg) } \\
\hline End of November & 47,5 & 92,0 & 48,1 & 137,0 & 114,4 & 87,8 & 0,86 & $* * *$ \\
\hline End of December & 50,7 & 67,1 & 76,6 & 124,1 & 95,7 & 82,8 & 1,29 & $* * *$ \\
\hline End of January & 52,3 & 53,2 & 103,5 & 141,2 & 116,7 & 93,4 & 1,03 & $* * *$ \\
\hline Mean & 50,1 & 70,8 & 76,1 & 134,1 & 108,9 & 88,0 & & \\
\hline SEM & 0,72 & 0,94 & 1,00 & 1,34 & 1,24 & & & \\
\hline \multirow[t]{2}{*}{ Sig. } & $* * *$ & $* * *$ & $* * *$ & $* * *$ & $* * *$ & & & \\
\hline & \multicolumn{8}{|c|}{ Peroxide Number (meq/Kg) } \\
\hline End of November & 8,0 & 13,6 & 10,0 & 14,0 & 7,1 & 10,5 & 0,41 & $* * *$ \\
\hline End of December & 9,9 & 13,9 & 7,8 & 11,6 & 5,8 & 9,8 & 0,11 & $* * *$ \\
\hline End of January & 10,2 & 11,4 & 12,0 & 16,6 & 17,4 & 13,5 & 0,28 & $* * *$ \\
\hline Mean & 9,4 & 13,0 & 9,9 & 14,1 & 10,1 & 11,3 & & \\
\hline SEM & 0,19 & 0,12 & 0,10 & 0,13 & 0,58 & & & \\
\hline \multirow[t]{2}{*}{ Sig. } & $* * *$ & $* * *$ & $* * *$ & $* * *$ & $* * *$ & & & \\
\hline & \multicolumn{8}{|c|}{$\mathrm{UV} \mathrm{K}_{232}$} \\
\hline End of November & 1,92 & 1,85 & 1,70 & 1,94 & 1,75 & 1,83 & 0,072 & $*$ \\
\hline End of December & 2,18 & 1,96 & 1,89 & 1,76 & 1,45 & 1,85 & 0,051 & $* * *$ \\
\hline End of January & 1,53 & 2,02 & 2,10 & 1,89 & 2,20 & 1,95 & 0,053 & $* * *$ \\
\hline Mean & 1,88 & 1,94 & 1,90 & 1,86 & 1,80 & 1,88 & & \\
\hline SEM & 0,056 & 0,047 & 0,041 & 0,057 & 0,044 & & & \\
\hline \multirow[t]{2}{*}{ Sig. } & $* * *$ & $*$ & $* * *$ & $*$ & $* * *$ & & & \\
\hline & \multicolumn{8}{|c|}{ UV K $K_{270}$} \\
\hline End of November & 0,16 & 0,20 & 0,17 & 0,18 & 0,23 & 0,19 & 0,009 & $* * *$ \\
\hline End of December & 0,23 & 0,17 & 0,20 & 0,21 & 0,20 & 0,20 & 0,007 & $* * *$ \\
\hline End of January & 0,17 & 0,19 & 0,20 & 0,20 & 0,19 & 0,19 & 0,008 & $* * *$ \\
\hline Mean & 0,19 & 0,19 & 0,19 & 0,19 & 0,21 & 0,19 & & \\
\hline SEM & 0,007 & 0,008 & 0,008 & 0,005 & 0,006 & & & \\
\hline \multirow[t]{2}{*}{ Sig. } & $* * *$ & $*$ & $*$ & $* * *$ & $* *$ & & & \\
\hline & \multicolumn{8}{|c|}{ Chlorophyll (ppm) } \\
\hline End of November & 9,73 & 2,98 & 3,27 & 2,09 & 0,85 & 3,79 & 0,059 & $* * *$ \\
\hline End of December & 2,78 & 2,35 & 11,08 & 3,46 & 0,60 & 4,05 & 0,070 & $* * *$ \\
\hline End of January & 1,51 & 1,87 & 2,26 & 1,37 & 1,04 & 1,61 & 0,051 & $* * *$ \\
\hline Mean & 4,67 & 2,40 & 5,54 & 2,31 & 0,83 & 3,15 & & \\
\hline SEM & 0,058 & 0,084 & 0,051 & 0,056 & 0,042 & & & \\
\hline \multirow[t]{3}{*}{ Sig. } & $* * *$ & $* * *$ & $* * *$ & $* * *$ & $* * *$ & & & \\
\hline & Site A & Site B & Site C & Site D & Site F & Mean & SEM & Sig \\
\hline & \multicolumn{8}{|c|}{ Methyl Palmitate \% } \\
\hline End of November & 10,83 & 16,52 & 10,22 & 15,38 & 16,37 & 13,86 & 0,101 & $* * *$ \\
\hline End of December & 9,51 & 12,15 & 11,57 & 16,14 & 15,99 & 13,07 & 0,092 & $* * *$ \\
\hline
\end{tabular}




\begin{tabular}{|c|c|c|c|c|c|c|c|c|}
\hline End of January & 9,06 & 8,77 & 13,11 & 16,02 & 15,47 & 12,49 & 0,055 & $* * *$ \\
\hline Mean & 9,80 & 12,48 & 11,63 & 15,85 & 15,94 & 13,14 & & \\
\hline SEM & 0,065 & 0,067 & 0,052 & 0,119 & 0,062 & & & \\
\hline Sig. & $* * *$ & $* * *$ & $* * *$ & $* * *$ & $* * *$ & & & \\
\hline & \multicolumn{8}{|c|}{ Methyl Palmitoleate \% } \\
\hline End of November & 0,14 & 0,77 & 0,14 & 0,90 & 0,79 & 0,55 & 0,031 & $* * *$ \\
\hline End of December & 0,06 & 0,23 & 0,50 & 0,91 & 0,62 & 0,47 & 0,096 & * \\
\hline End of January & 0,08 & 0,15 & 0,38 & 0,69 & 0,72 & 0,40 & 0,076 & $* * *$ \\
\hline Mean & 0,09 & 0,38 & 0,34 & 0,83 & 0,71 & 0,47 & & \\
\hline SEM & 0,037 & 0,039 & 0,012 & 0,017 & 0,014 & & & \\
\hline \multirow[t]{2}{*}{ Sig. } & $* * *$ & *** & *** & $* * *$ & $* * *$ & & & \\
\hline & \multicolumn{8}{|c|}{ Methyl Stearate \% } \\
\hline End of November & 3,11 & 2,48 & 2,80 & 2,15 & 1,83 & 2,47 & 0,055 & $* * *$ \\
\hline End of December & 2,75 & 2,50 & 2,89 & 1,94 & 2,13 & 2,44 & 0,037 & $* * *$ \\
\hline End of January & 2,92 & 2,82 & 2,50 & 2,18 & 2,30 & 2,54 & 0,088 & $* * *$ \\
\hline Mean & 2,93 & 2,60 & 2,73 & 2,09 & 2,09 & 2,49 & & \\
\hline SEM & 0,059 & 0,034 & 0,059 & 0,045 & 0,054 & & & \\
\hline \multirow[t]{2}{*}{ Sig. } & $* * *$ & $* * *$ & *** & ** & $* * *$ & & & \\
\hline & \multicolumn{8}{|c|}{ Methyl Oleate \% } \\
\hline End of November & 80,37 & 73,78 & 80,83 & 73,23 & 73,80 & 76,40 & 0,378 & $* * *$ \\
\hline End of December & 82,40 & 78,21 & 79,51 & 74,37 & 74,93 & 77,88 & 0,185 & $* * *$ \\
\hline End of January & 82,62 & 81,80 & 78,62 & 73,59 & 75,68 & 78,46 & 0,148 & $* * *$ \\
\hline Mean & 81,80 & 77,93 & 79,66 & 73,73 & 74,80 & 77,58 & & \\
\hline SEM & 0,466 & 0,219 & 0,179 & 0,111 & 0,148 & & & \\
\hline \multirow[t]{2}{*}{ Sig. } & $* * *$ & $* * *$ & $* * *$ & $* * *$ & $* * *$ & & & \\
\hline & \multicolumn{8}{|c|}{ Methyl Linoleate \% } \\
\hline End of November & 5,46 & 6,35 & 6,65 & 7,48 & 6,34 & 6,46 & 0,068 & $* * *$ \\
\hline End of December & 5,48 & 5,57 & 5,74 & 6,64 & 6,03 & 5,89 & 0,047 & $* * *$ \\
\hline End of January & 5,37 & 6,06 & 5,06 & 7,16 & 5,90 & 5,91 & 0,044 & $* * *$ \\
\hline Mean & 5,43 & 6,00 & 5,82 & 7,09 & 6,09 & 6,09 & & \\
\hline SEM & 0,039 & 0,042 & 0,039 & 0,083 & 0,050 & & & \\
\hline \multirow[t]{2}{*}{ Sig. } & $* * *$ & $* * *$ & *** & $* * *$ & $* * *$ & & & \\
\hline & \multicolumn{8}{|c|}{ Methyl Linolenate $\%$} \\
\hline End of November & 0,13 & 0,11 & 0,21 & 0,22 & 0,14 & 0,16 & 0,004 & $* * *$ \\
\hline End of December & 0,12 & 0,09 & 0,08 & 0,13 & 0,27 & 0,14 & 0,003 & $* * *$ \\
\hline End of January & 0,15 & 0,20 & 0,13 & 0,18 & 0,18 & 0,17 & 0,004 & $* * *$ \\
\hline Mean & 0,13 & 0,13 & 0,14 & 0,18 & 0,20 & 0,16 & & \\
\hline SEM & 0,004 & 0,003 & 0,004 & 0,002 & 0,004 & & & \\
\hline Sig. & $* * *$ & $* * *$ & $* * *$ & $* * *$ & $* * *$ & & & \\
\hline
\end{tabular}

\section{References}

[1] H. Jabeur, A. Zribi, M. Bouaziz, (2017). Changes in chemical and sensory characteristics of Chemlali extra-virgin olive oil as depending on filtration. European Journal of Lipid Science and Technology, 119, 1500602 (1 of 10).

[2] N. Kalogeropoulos and M. Tsimidou, (2014). Antioxidants in Greek virgin olive oils. Antioxidants 3, 387-413

[3] M. Sarolie, M. Gugić, E. Friganović, C. I. G. Tuberoso and I. Jerković, (2015). Phytochemicals and Other Characteristics of Croatian Monovarietal Extra Virgin Olive Oils from Oblica, Lastovka and Levantinka Varieties. Molecules, 20, 4395-4409.

[4] S. Bedbabis, B. Ben Rouina, C. Salvatore and M.-L. Clodoveo, (2015). Effect of the seasonal climatic variations on the composition and quality of "Chemlali" virgin olive oil. African Journal of Agricultural Research, 10(49), 4424-4431.

[5] A. Piscopo, A. De Bruno, A. Zappia, C. Ventre, M. Poiana, (2016). Characterization of monovarietal olive oils obtained from mills of Calabria region (Southern Italy). Food Chemistry, 213, 313-318.

[6] O. Okogeri, (2002). Changes in the composition of antioxidants in Greek olive oils during storage. Doctorate Thesis, Ioannina. 
[7] European Union Commission (2013). Commission Implementing Regulation No 1348/2013 of December 17 2013. Official Journal of the European Union, L. 338, 31-67.

[8] IUPAC. Standard methods for the analysis of oils, fats and derivatives. Methods 2501 and $2505\left(7^{\text {th }}\right.$ ed. International Union of Pure and Applied Chemistry, London: Blackwell scientific Publication, 1987.

[9] AOCS. Official Methods and Recommended practices of the American Oil Chemists' Society, $3^{\text {rd }}$ ed Method Cc 13d-55, 1989.

[10] G. W. Snedecor and W.G. Cochran, Statistical methods. 8th edition. Iowa State University Press, (Ames, Iowa, 1989), 503.

[11] R. G. Steel and J. H. Torrie, Principles and Procedures of Statistics. McGraw-Hill Book Co., New York, (NY, USA, 1980), 633.

[12] A. Daga, Z. Keremb, N. Yogevb, I. Ziporia, S. Laveec, E. Ben-Davida, (2011). Influence of time of harvest and maturity index on olive oil yield and quality. Scientia Horticulturae 127(3), 358-366

[13] M. Tasioula-Margari, O. Okogeri, (2001). Simultaneous determination of phenolic compounds and tocopherols in virgin olive oil using HPLC and UV detection. Food Chemistry, 74, 377-383.

[14] E. Psomiadou, M. Tsimidou, (1998). Simultaneous HPLC determination of tocopherols carotenoids and chlorophylls for monitoring their effect on virgin olive oil oxidation. Journal of Agricultural and Food Chemistry, 46, 5132-5138.

[15] M. Poiana, A. Mincione, A. M. Giuffre, B. Mincione, (2001). Ricerche sugli oli di oliva monovarietali. Nota XI Contributo alla caratterizzazione dell'olio estratto dale olive della cv Leccino coltivata in provincia di Reggio calabria. Larivista Italiana delle sostanze grasse, Vol LXXVIII, 93115.

[16] S. Lo Curto, M. Saitta, G. Di Bella, E. Mavrogeni, F. Salvo, G. Dugo, (2001). Caratterizzazione di oli di oliva vergini sicilliani. Nota VII. Larivista Italiana delle sostanze grasse, Vol LXXVIII, 511524.

[17] European Union Commission Regulation (EU) 2095/2016 of 26 September, 2016. Commission Regulation amending Regulation (EEC) No 2568/91 on the characteristics of olive oil and oliveresidue oil and on the relevant methods of analysis. Official Journal of the European Union L 326, 16.

[18] E. Anastasopoulos, N. Kalogeropoulos, A. C. Kaliora, A. Falirea, V. N. Kamvissis, N. K. Andrikopoulos, (2012). Quality Characteristics and Antioxidants of Mavrolia cv. Virgin Olive Oil. Journal American Oil Chemists' Society 89, 253-259.

[19] M. Issaoui, G. Flamini, F. Brahmi, S. Dabbou, K. Ben Hassine, A. Taamali, H. Chehab, M. Ellouz, M. Zarrouk, M. Hammamia, (2010). Effect of the growing area conditions on differentiation between Chemlali and Chitoui olive oils. Food Chemistry 119, 220-225.

[20] Y. Ouni, G. Flamini, M. Issaoui, Y. Nabil Ben, P. L. Cioni, M. Hammami, D. Douja, M. Zarrouk, (2011). Volatile compounds and compositional quality of virgin olive oil from Oueslati variety: Influence of geographical origin. Food Chemistry 124, 1770-1776

[21] B. Gargouri, S. Ammar, A. Zribi, A. B. Mansour, M. Bouaziz, (2013). Effect of growing region on quality characteristics and phenolic compounds of chemlali extra-virgin olive oils. Acta Physiol Plant, 35, 2801-2812. 